\title{
Pneumonia risk of people living close to goat and poultry farms - Taking GPS derived mobility patterns into account
}

\author{
Gijs Klous ${ }^{\mathrm{a}, \mathrm{b}, *}$, Lidwien A.M. Smit ${ }^{\mathrm{b}}$, Gudrun S. Freidl ${ }^{\mathrm{c}, \mathrm{d}}$, Floor Borlée ${ }^{\mathrm{b}, \mathrm{e}}$, Wim van der Hoek ${ }^{\mathrm{c}}$, \\ C. Joris IJzermans ${ }^{\mathrm{e}}$, Mirjam E.E. Kretzschmar ${ }^{\mathrm{a}, \mathrm{c}}$, Dick J.J. Heederik ${ }^{\mathrm{b}}$, Roel A. Coutinho ${ }^{\mathrm{a}, \mathrm{f}}$, \\ Anke Huss ${ }^{\mathrm{b}}$ \\ a Julius Centre for Health Sciences and Primary Care, University Medical Centre Utrecht, The Netherlands \\ ${ }^{\mathrm{b}}$ Institute for Risk Assessment Sciences, Division Environmental Epidemiology and Veterinary Public Health, Utrecht University, The Netherlands \\ ${ }^{c}$ National Institute for Public Health and the Environment (RIVM), The Netherlands \\ d European Programme for Intervention Epidemiology Training \\ e Netherlands Institute for Health Services Research (NIVEL), The Netherlands \\ ${ }^{\mathrm{f}}$ Faculty of Veterinary Medicine, Utrecht University, The Netherlands
}

\section{A R T I C L E I N F O}

Handling Editor: Yong Guan Zhu

\begin{abstract}
A B S T R A C T
We previously observed an increased incidence of pneumonia in persons living near goat and poultry farms, using animal presence around the home to define exposure. However, it is unclear to what extent individual mobility and time spent outdoors close to home contributes to this increased risk. Therefore, the aim of the current study was to investigate the role of mobility patterns and time spent outdoors in the vicinity of goat or poultry farms in relation to pneumonia risk.

In a rural Dutch cohort, 941 members logged their mobility using GPS trackers for 7 days. Pneumonia was diagnosed in 83 subjects (participants reported that pneumonia had been diagnosed by a medical doctor, or recorded in EMR from general practitioners, 2011-2014). We used logistic regression to evaluate pneumoniarisk by presence of goat farms within 500 and $1000 \mathrm{~m}$ around the home and around GPS-tracks (only nonmotorised mobility), also we evaluated whether more time spent outdoors increased pneumonia-risks.

We observed a clearly increased risk of pneumonia among people living in close proximity to goat farms, ORs increased with closer distances of homes to farms (500 m: 6.2 (95\% CI 2.2-16.5) $1000 \mathrm{~m}: 2.5$ (1.4-4.3)) The risk increased for individuals who spent more time outdoors close to home, but only if homes were close to goat farms (within $500 \mathrm{~m}$ and often outdoors: 12.7 (3.6-45.4) less often: 2.0 (0.3-9.2), no goat farms and often outdoors: 1.0 (0.6-1.6)). For poultry we found no increased risks.

Pneumonia-risks increased when people lived near goat farms, especially when they spent more time outdoors, mobility does not seem to add to these risks.
\end{abstract}

\section{Introduction}

The Netherlands is a densely populated country with a land surface of $41.500 \mathrm{~km}^{2}$ (www.cbs.nl, n.d.-a) and a population of approximately 17 million people (www.cbs.nl, n.d.-b). Intensive farming in the Netherlands is an important economic activity and the country has a large livestock population of approximately 124 million animals (data from 2016: 0.5 million goats, 0.8 million sheep, 4.3 million cattle, 12.5 million pigs, 105.5 million poultry) (www.cbs.nl, n.d.-c), clustered in specific areas (Fig. 1). Associations between livestock animals and the potential for zoonotic disease transmissions have come to attention globally (Klous et al., 2016). Given the close proximity of people and livestock, the Netherlands is considered to be at high risk for the emergence of livestock-associated zoonotic diseases (Jones et al., 2008). This was illustrated in the past decade by the presence of antibiotic resistant bacteria in livestock animals with spill-over to humans (Graveland et al., 2011; Wielders et al., 2017) and the largest reported Q-fever outbreak to date, originating from infected pregnant goats (Van Der Hoek et al., 2012). These events have renewed interest into the potential effects of livestock production on human health, which led to

\footnotetext{
* Corresponding author at: IRAS EEPI-VPH Utrecht University, Yalelaan 2, 3584 CM Utrecht, The Netherlands.

E-mail addresses: g.klous@umcutrecht.nl (G. Klous), l.a.smit@uu.nl (L.A.M. Smit), gudrun.freidl@rivm.nl (G.S. Freidl), f.borlee@uu.nl (F. Borlée), wim.van.der.hoek@rivm.nl (W. van der Hoek), j.yzermans@nivel.nl (C.J. IJzermans), m.e.e.kretzschmar@umcutrecht.nl (M.E.E. Kretzschmar), d.heederik@uu.nl (D.J.J. Heederik), r.a.coutinho@umcutrecht.nl (R.A. Coutinho), a.huss@uu.nl (A. Huss).
} 

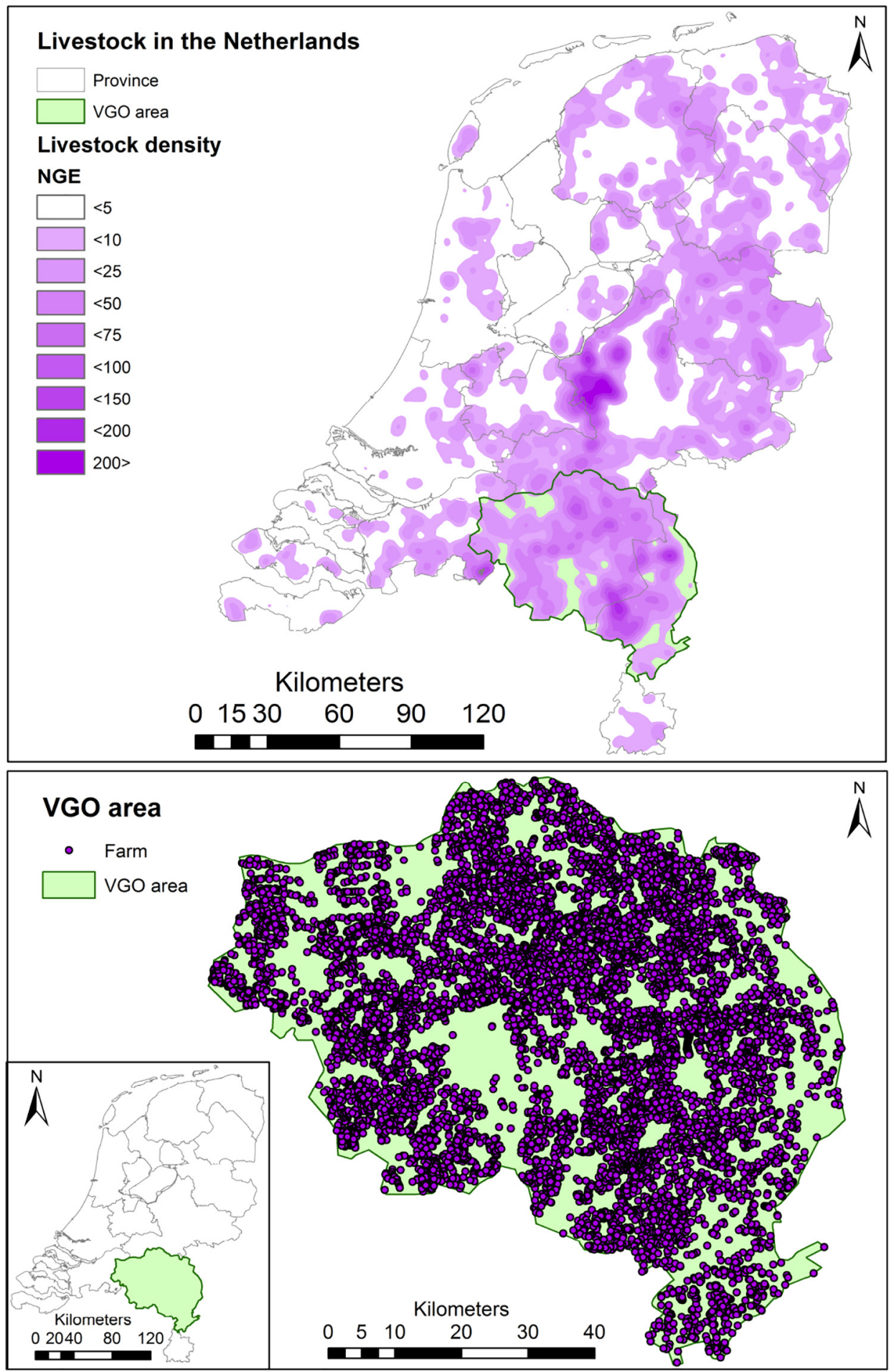

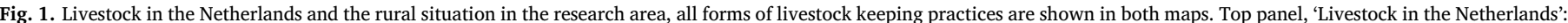

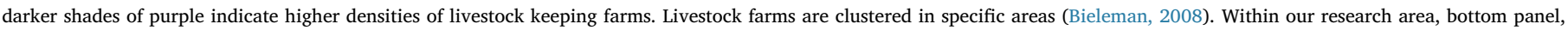

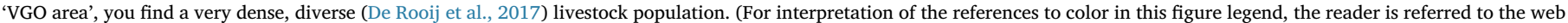
version of this article.)

the start of the large "Farming and Neighbouring Residents' Health" study in 2012 (Dutch acronym: VGO). The main goal of this study is to investigate whether living in the vicinity of livestock farms has an impact on the health of residents (Borlée et al., 2015).

The main findings of the VGO study include a significantly increased incidence of pneumonia among people living close to goat and poultry farms (odds ratios 4.4 and 2.0 for persons living within $500 \mathrm{~m}$ and $1000 \mathrm{~m}$ of a goat farm and 1.3 and 1.7 for living within $500 \mathrm{~m}$ and
$1000 \mathrm{~m}$ of a poultry farm). However, this increased risk was not observed for other farms such as cattle and pig farms (Freidl et al., 2017; Smit et al., 2017). Freidl et al. used the home address as a proxy of exposure. However, people are mobile which might also be relevant for their exposure. We recently assessed the daily mobility (Klous et al., 2017) of a representative subsample (Supp. Table 1, (Borlée et al., 2015; Freidl et al., 2017; Borlée et al., 2017)) of the VGO cohort study to enable exploring differences in exposure to livestock based on the 


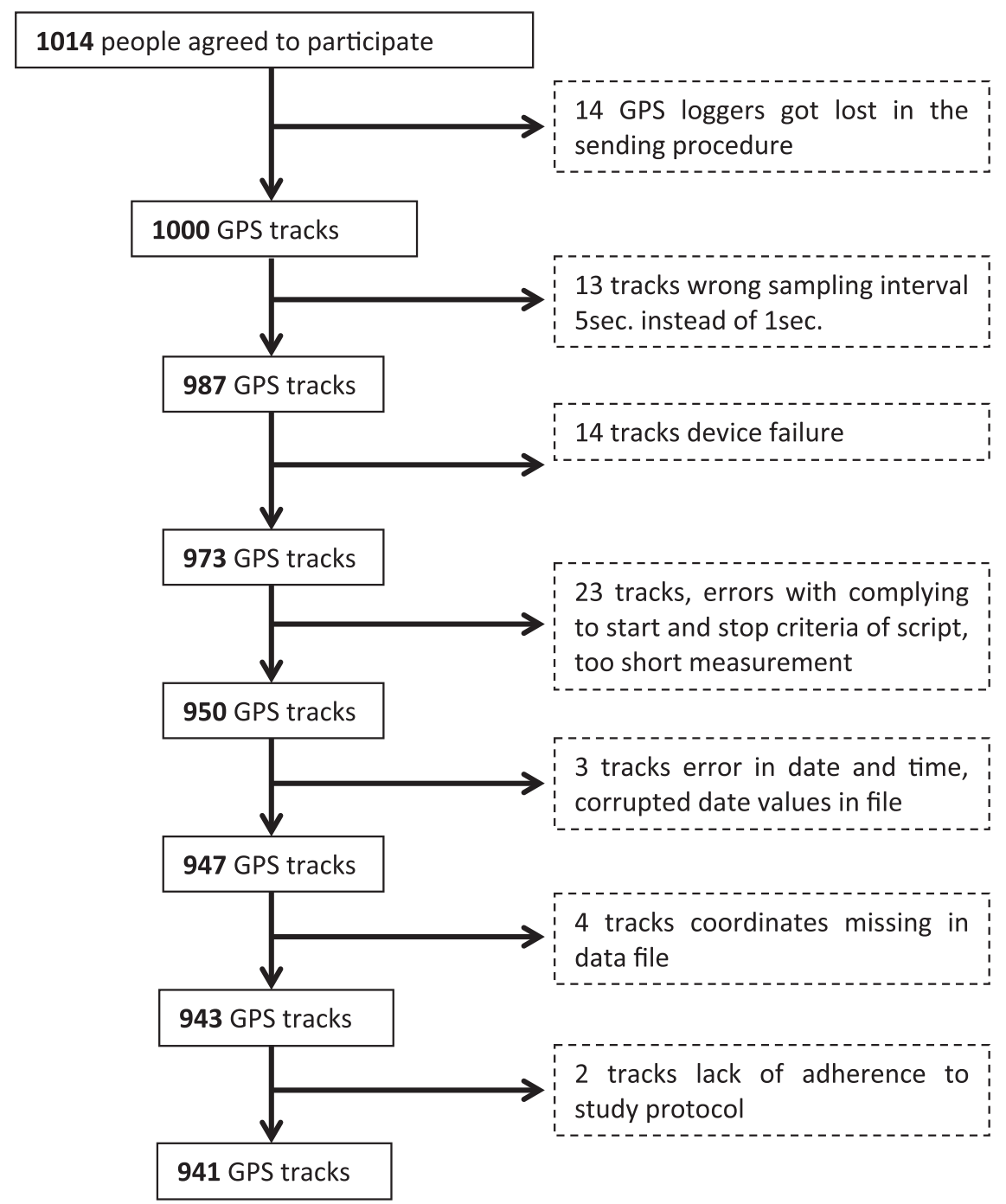

Fig. 2. Data cleaning flowchart.

home address and on mobility patterns.

The aim of the current study was to investigate the role of mobility patterns and time spent outdoors in the vicinity of goat or poultry farms in relation to pneumonia risk.

\section{Methods}

\subsection{Population and health data}

Participants in the VGO cohort $(N=2494)$ were living in a rural area in the south-eastern part of the Netherlands (Fig. 1). Farmers and people living or working on farms were excluded a priori, since the focus was on the health of residents living in the vicinity of farms. VGO cohort members underwent a medical examination (lung function measurements, blood, nasal- and buccal-epithelia collection, stool sample) in a field study that took place between March 2014 and February 2015. During this medical examination, participants also filled in a baseline questionnaire (VGO questionnaire), including questions about personal characteristics, health and lifestyle (Borlée et al., 2015; Freidl et al., 2017).

Additional health information for 2426 out of the 2494 (97\%) participants was obtained from electronic medical records (EMR) of 27 participating general practitioners (GPs). In the Netherlands, every citizen is obliged to register with a general practitioner who acts as gatekeeper to specialised care. EMR data was used in the study if permission was granted from participants and specific quality criteria for registering were met by GPs. The quality requirements to be met be GPs are broadly as follows: 1) GPs were required to register health data in the EMR using the codes defined in the International Classification of Primary Care (ICPC) (Lamberts and Wood, 1987); 2) ICPC codes had to be assigned to at least $50 \%$ of the records in the EMR; and 3) GP practices recorded consultations for $>6$ months during a year (Borlée et al., 2015; Smit et al., 2012; van Dijk et al., 2017). Sixty-eight of the 2494 VGO participants were excluded from analysis because either EMR access was refused or EMR data was not available. Therefore, the final population of the VGO study was 2426 individuals (Freidl et al., 2017), of which 2370 (98\%) provided consent to be contacted for subsequent research. Subsequent to the VGO study, multiple follow-up studies were initiated (ESBL screening, COPD follow-up). If people were not invited for these other studies, they were invited for the current (GPS) study. Participants of the COPD follow-up were afterwards also invited to participate in the GPS study. Therefore, from the VGO population, 1517 participants were invited for the GPS study and a total of 1014 invitees (66.8\%) agreed to participate (Klous et al., 2017). Medical Ethical approval was obtained for the VGO study from the Medical Ethical Committee of the University Medical Centre Utrecht (protocol number 13/533). 


\subsection{Pneumonia case definition}

People were considered to be diagnosed with pneumonia if they reported a physician-diagnosed pneumonia in the past three years in the VGO questionnaire. In addition, EMRs were reviewed for a GPs registration of pneumonia within the last three years (ICPC code R81) (Lamberts and Wood, 1987). If participants did not report a pneumonia in the VGO questionnaire, but R81 was registered in their EMR between 2011 and 2015, these participants were also considered as pneumonia cases.

\subsection{Global Positioning System (GPS) data and self-reported time spent outdoors, data collection and cleaning}

The procedures of the VGO GPS study are described in more detail in Klous et al. (2017). In brief, between September 2014 and January 2016, 1014 volunteers logged their movements by carrying a GPS logger for 7 consecutive days. GPS devices were set to a one-second interval and only logged when the devices were moved. A total of 941 GPS tracks were available for the current analyses. The main reasons for exclusion were primarily device configuration errors $(5 \mathrm{~s}$ instead of $1 \mathrm{~s}$ sampling interval, $N=13)$, GPS device failure $(N=14)$, or postal errors, an overview is given in Fig. 2. Based on GPS measured speed patterns, transport modes were assigned to GPS points that were located outdoors (Klous et al., 2017; Huss et al., 2014). Indoors/outdoors assignment of GPS locations was done using the participants' home address coordinates using cadastral data from the Netherlands (BAG data 2015) (see Fig. 3 for an overview of GPS data processing). Assigned transport modes were walking, biking, or motorised transport.

Before GPS logging, participants filled in a questionnaire (Q1) containing questions on the number of hours per week they spent outdoors close to their homes ("in a usual week how many hours do you spend outdoors close to home e.g. gardening, care for animals, do-ityourself activities, sitting in the garden") (Klous et al., 2017). As we used a $60 \mathrm{~m}$ buffer around the home address to assign a GPS point as being indoors or outdoors (Klous et al., 2017), time spent outdoors while remaining close to home could not be determined solely using GPS measurements. Therefore, we used answers to the question about time spent outdoors while close to home to specify these durations.

\subsection{Geographic Information System (GIS) analyses}

\subsubsection{Animals in the vicinity of the home address and GPS-measured mobility}

In line with the previous analysis by Freidl et al. (2017), we used the database of livestock-keeping companies (Dutch abbreviation: BVBdatabase) 2015 to assess how many goats and poultry were registered within $500 \mathrm{~m}$ and $1000 \mathrm{~m}$ distances around home addresses. The BVB registry includes permit registrations for farms, with information pertaining to location of the farm, and types and numbers of animals (Noord-Brabant, n.d.; Limburg, n.d.). In concordance with Freidl et al, to evaluate the presence or absence of goats or poultry in the vicinity of the homes for our main analysis, we required a minimum of 50 goats or 250 chickens in our distance categories of 500 and $1000 \mathrm{~m}$ (Freidl et al., 2017). The number of animals required for a farm to be officially registered as such. Note that according to Statistics Netherlands, $>98 \%$ of animals registered as 'poultry' are chicken therefore we assume that all records of poultry refer to chicken (www.cbs.nl, n.d.-c; www.wur.nl, n.d.).

Of all participants' location coordinates measured with GPS, we only evaluated those that related to active transport modes (outdoor points grouped as 'walking' or 'biking'), as these were assumed to be relevant for exposure to the outdoor environment. Any GPS coordinate that fell within $500 \mathrm{~m}$ or $1000 \mathrm{~m}$ of any goat or poultry farm was classified as "exposed". We then summarised per person the amount of time spent outdoors in "exposed" locations, or if all GPS locations could be grouped as "unexposed".

\subsubsection{Self-reported time spent outdoors close to home}

We used questionnaire data about time spent outdoors to assign the duration of time spent outdoors close to home. Based on the median duration $(3.5 \mathrm{~h} /$ week) that participants reported to spend outdoors close to home (e.g. gardening, care for animals, do-it-yourself activities, sitting in the garden), this variable was dichotomised $(0-3.5 \mathrm{~h}$ /week versus $>3.5-62.5 \mathrm{~h} /$ week)

\subsection{Statistical analyses}

We evaluated pneumonia risk related to the presence of goat and poultry farms within 500 or $1000 \mathrm{~m}$ of either the home address, GPS track (GPS-measured "exposed" active mobility: walking or biking), or both. We further evaluated whether time spent outdoors close to home while living close to farms had an effect on pneumonia risk. We used logistic regression to evaluate pneumonia risk, adjusted for age, sex, educational level (low, medium, high) and smoking status (current, ever, never). Some people might be exposed to both goats and poultry, and the corresponding Spearman's correlation coefficients for number of registered goats and chicken within 500 and $1000 \mathrm{~m}$ were 0.37 and 0.31 , respectively. We therefore adjusted our main analysis also for presence or absence of the respective other animal type near home.

\subsection{Sensitivity analyses}

We performed several sensitivity analyses.

(A) Animal intensity: In our main analysis we considered 50 goats or 250 chickens as cut-off to indicate farms. This implies that some participants may be categorised as unexposed, while they could have been exposed to lower numbers of animals in the vicinity of their homes. Therefore, we performed sensitivity analyses on the number of animals registered within the 500 or $1000 \mathrm{~m}$ distance buffer around participants' homes. In this analysis, we assigned "low" animal intensity category to persons living within 500 or $1000 \mathrm{~m}$ from farms with 1-49 goats or 1-249 chickens. We additionally categorised animal intensity as "medium" or "high", by applying the cut-off at the median of registered animal numbers (1659 and 384 goats within 500 and $1000 \mathrm{~m}$, respectively and 13,480 and 37,160 chickens within 500 and $1000 \mathrm{~m}$, respectively). This means we assigned "medium" animal intensity for the residential presence of goats and poultry if participants lived within 500 or $1000 \mathrm{~m}$ of $50-1658$ or $50-383$ goats or $250-13,479$ or $250-37,159$ chickens, or "high" for living within 500 or $1000 \mathrm{~m}$ from $\geq 1659-3250$ goats or $\geq 384-5015$ goats, or $\geq 13,480-290,600$ chickens or $\geq 37,160-694,900$ chickens, respectively. See Supp. Table 2 for a summary of the used cut-offs.

(B) Case definition: We restricted our pneumonia cases to participants with an R81 registration (pneumonia) in their GPs electronic medical records ( $N=55,66 \%$ of cases based on the original case definition).

(C) Spline analysis: We explored the shape of the association between pneumonia risk and total time spent outdoors in the vicinity of goat or poultry farms using penalised regression splines applying the (default) 'thin plate' basis of the R package mgcv (mixed generalised additive model computation vehicle). For these analyses, all 'goat-exposed time' was combined, so GPS-measured 'exposed' active mobility (walking, biking) was added to self-reported 'exposed' time spent outdoors close to home, thus accumulating into one 'exposed time variable'. This was done separately for the different buffer sizes (500 or $1000 \mathrm{~m}$ ). We also performed the same analysis for exposure to poultry farms.

(D) Full VGO cohort: We repeated our main analysis in the full VGO cohort using the VGO baseline questionnaire to extract information 


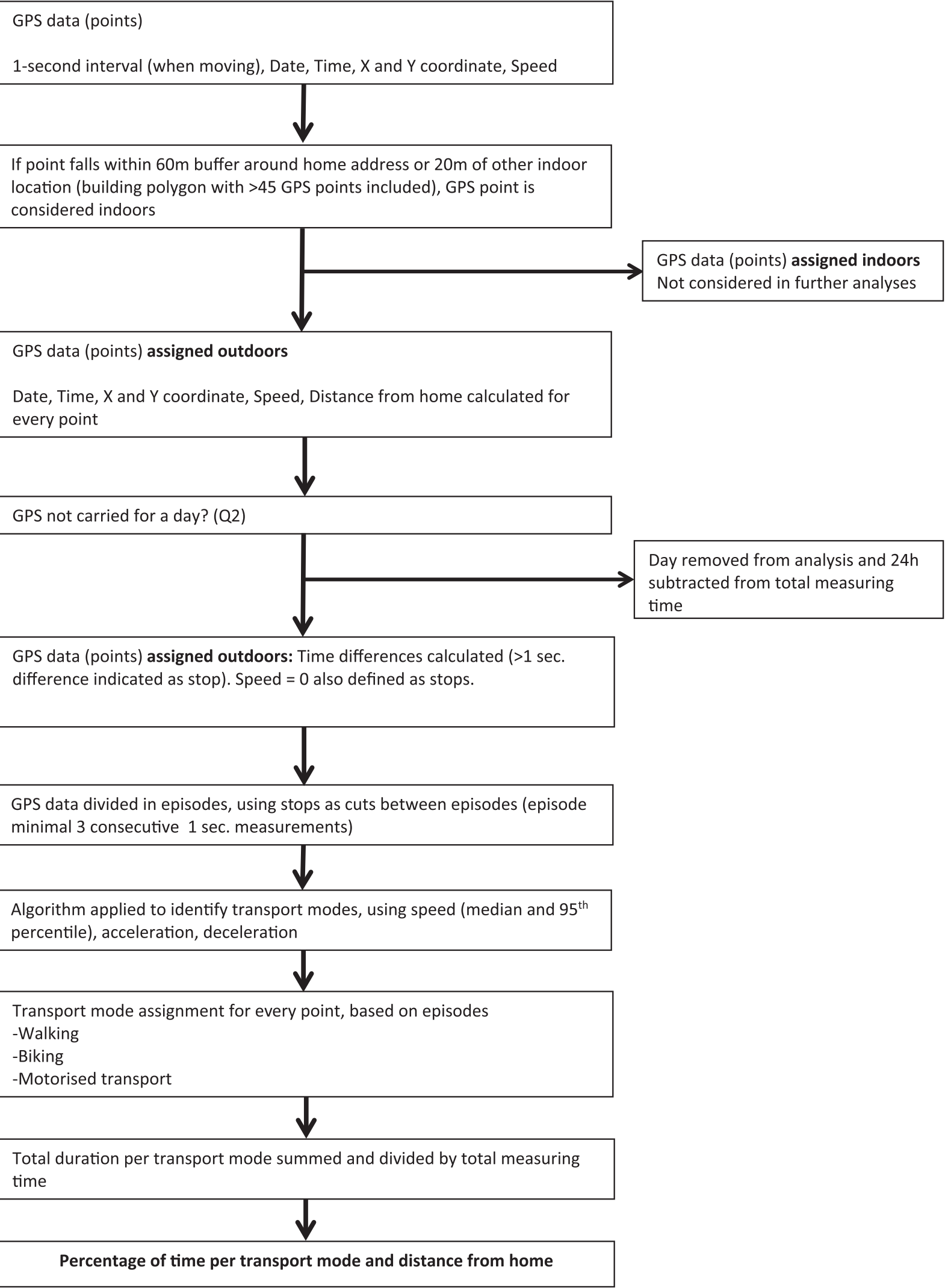

Fig. 3. Schematic of GPS data processing.

on time spent outdoors close to home. In this analysis, the same case definition was applied as for the GPS study.

(E) Invitation selection and non-responder analyses, we compared invited and non-invited VGO cohort members and participants and invited non-responders for: outcome category, age, gender, educational level, smoking status and goat and poultry exposure.

All statistical analyses were performed using R (3.2.3), and all GIS 
Table 1

General characteristics of study population.

\begin{tabular}{|c|c|c|c|}
\hline \multicolumn{2}{|l|}{ Variable } & Pneumonia cases & Controls \\
\hline \multicolumn{2}{|c|}{ Number of participants $(N=)$} & 83 & 858 \\
\hline \multicolumn{2}{|c|}{ Age (mean (range)) } & $60(31-72)$ & $57(20-72)$ \\
\hline \multicolumn{2}{|l|}{ Gender (females (\%)) } & $54(65 \%)$ & $464(54 \%)$ \\
\hline \multirow[t]{3}{*}{ Education $(N=(\%))$} & Low & $30(36 \%)$ & $202(24 \%)$ \\
\hline & Medium & $32(39 \%)$ & $392(46 \%)$ \\
\hline & High & $21(25 \%)$ & $264(31 \%)$ \\
\hline \multirow[t]{4}{*}{ Smoking $(N=(\%))$} & Never & $25(30 \%)$ & $352(41 \%)$ \\
\hline & Former & $52(63 \%)$ & $435(51 \%)$ \\
\hline & Current & $6(7 \%)$ & $68(8 \%)$ \\
\hline & No data & & $3(0.3 \%)$ \\
\hline \multicolumn{2}{|c|}{$\begin{array}{l}\text { Time spent outdoors close to home } \\
\text { (hours/week (median, IQR)) }\end{array}$} & $4.0(2.0-7.0)$ & $3.5(1.5-7.5)$ \\
\hline \multicolumn{2}{|c|}{ Time walking (min/week (median IQR)) } & $19.8(8.4-40.2)$ & $19.7(7.8-55.2)$ \\
\hline \multicolumn{2}{|c|}{ Time biking (min/week (median IQR)) } & $\begin{array}{l}76.3 \\
(17.4-140.1)\end{array}$ & $59.9(15.9-147.6)$ \\
\hline
\end{tabular}

analyses were performed with ArcGIS ArcMap 10.2 (ESRI, Redlands, CA, USA) and automated using Python 2.7.

\section{Results}

The average age of the 941 participants was 57 years (range 20-72 years) and 55\% of the participants were women. A total of, 26 (3\%) participants lived within $500 \mathrm{~m}$ of a goat farm, $116(12 \%)$ within $1000 \mathrm{~m}$ of a goat farm and $151(16 \%)$ and $416(44 \%)$ within $500 \mathrm{~m}$ and $1000 \mathrm{~m}$ of a poultry farm, respectively. Overall, 83 participants $(8.8 \%)$ reported a pneumonia diagnosis in the past three years (2011-2015) or reported to have been diagnosed by their GP with pneumonia (of which 55 [66\% of total cases] had an R81 registration in the EMR). Of cases, $65 \%$ were female $(N=54)$ and their average age was 60 years (range 31-72 years), see Table 1. The subsample of individuals with GPS tracks did not differ significantly in terms of age, sex educational level and smoking habits from the total VGO cohort. There was however a difference in exposure categories, this is mainly explained by differences in sizes of the non-exposed groups (Supplementary Table 1). Between invited and non-invited VGO cohort members we observed a significant difference in group sizes of exposed participants (Supplementary Table 10). There was only a minor difference observed for age and smoking status between participants and non-responders of the VGO GPS study (Supplementary Table 11).

\subsection{Goats}

We found a distance-related increased risk for pneumonia associated with the presence of goats (see Table 2, unadjusted results are shown in Supp. Table 3). If people lived within $500 \mathrm{~m}$ of a farm with at least 50 goats, they had 6.2 times higher odds to be diagnosed with pneumonia (OR 6.2 (95\% CI 2.2-16.5) and for a farm with at least 50 goats within $1000 \mathrm{~m}$ of the home the OR was 2.5 (95\% CI 1.4-4.3). If the number of animals was categorised into "low", "medium" and "high" categories (using farms with $\geq 50$ animals and the median as cut-offs) an exposure-response trend was observed with an increasing risk for pneumonia with increasing categories of animal intensity (OR 1.0 for "low" and 2.5 for "high" goat intensity, there were no pneumonia cases within the "median" category (Supp. Table 3)). This relationship could only be observed for farms with goats within $1000 \mathrm{~m}$ of the home, since a similar analysis was not possible for goats within $500 \mathrm{~m}$ around the home because there were too few cases in the "low" and "medium" groups (1-49, 50-median).

Only a marginal change in the goat-associated risk for pneumonia was observed when mobility was taken into account (using $500 \mathrm{~m}$ buffers, OR 6.21 [95\% CI 2.2-16.9] for animals close to the home address plus mobility versus OR 6.15 [95\% CI 2.2-16.5] for animals close to the home address only). When we calculated the risk for pneumonia in relation to active mobility only (based on GPS monitoring), we found an OR of 1.03 (95\% CI 0.6-1.7). However, when time spent outdoors in the vicinity of the home (i.e. primarily gardening) was taken into account, we observed increasing risks of pneumonia when people were living within $500 \mathrm{~m}$ and $1000 \mathrm{~m}$ of goat farms. People living within $500 \mathrm{~m}$ of a goat farm who spent long periods in their garden had an OR of 12.7 (95\% CI 3.6-45.4), based on 7 cases and 7 controls, which was larger than that observed for people who spent shorter periods in their garden (OR 2.0 [95\% CI 0.3-9.2], based on 2 cases, 10 controls). No increased risks were observed for people who spent long periods in their gardens in unexposed locations, ORs were 1.0 for both 500 (95\% CI 0.6-1.6) and $1000 \mathrm{~m}$ (95\% CI 0.6-1.7) distance categories. For people living within $1000 \mathrm{~m}$ of a goat farm similar effects were observed. When people spent longer periods outdoors the OR was higher (OR 3.0 [95\% CI 1.4-6.2] versus OR 1.9 [95\% CI 0.8-4.1]). Similar patterns were observed when we restricted our cases to pneumonia cases registered in the GP electronic medical records (Supp. Table 5) or when we analysed the complete VGO population (Supp. Table 7).

\subsection{Poultry}

No statistically significantly increased pneumonia risks were observed for people living close to farms with 250 or more chickens in the vicinity of their home, (OR 1.1 [95\% CI 0.6-2.1] for poultry within $500 \mathrm{~m}$, OR 1.1 [95\% CI $0.7-1.8$ ] for poultry within $1000 \mathrm{~m}$ ) (see Table 3 and Supp. Table 4). ORs were above unity but not statistically significant for participants exposed at home and during active mobility. More time spent on mobility in exposed locations resulted in an OR of 1.5 (95\% CI 0.8-3.2) for a poultry farm within $500 \mathrm{~m}$ of a GPS track, for farms within $1000 \mathrm{~m}$ of the GPS track no such effect was observed. When we analysed re-categorised poultry density categories, based on number of chickens, we did not observe an exposure-response increase in pneumonia risk for higher chicken density (see Supp. Table 4). In addition, risk estimates for pneumonia from the presence or absence of poultry were attenuated when we adjusted for the presence of goats.

\subsection{Spline analyses}

Spline analyses suggested a linear association between total time spent outdoors in the vicinity of goat farms (both within 500 and $1000 \mathrm{~m}$ ) and increased risks for pneumonia. This relationship again was stronger for the presence of goat farms within $500 \mathrm{~m}$ of the home when more time was spent outdoors. However, the confidence intervals of the splines were very wide, especially for those participants who spent the most time outdoors (Fig. 4a and b). For poultry, these relationships were not observed, in line with the outcomes of the logistic regression analyses (Fig. 4c and d).

\section{Discussion}

We observed an increased risk of pneumonia in people living in close proximity to goat farms. ORs increased with closer distances of homes to farms and with increasing categories of animal intensity. Active mobility in the vicinity of goat farms only marginally added to pneumonia risk. However, the risk was increased for individuals who spent more time outdoors close to their home, but only if their homes were located in close proximity (i.e. within 500 or $1000 \mathrm{~m}$ ) to goat farms. Pneumonia risks for poultry farms in the vicinity of homes, during active mobility or for time spent outside was above unity but not statistically significantly elevated.

The observed increased risk of pneumonia in persons living close to goat farms is in line with the observation from Freidl et al. (2017), which is reassuring given that we analysed a subgroup of the VGO study. A few years before this study, between 2007 and 2009, the area had experienced the largest described Q-fever epidemic to date (Van 
Table 2

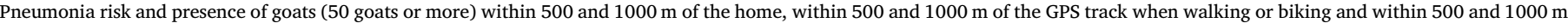
of the home while being outdoors (gardening).

\begin{tabular}{|c|c|c|c|c|c|c|c|}
\hline \multirow[t]{2}{*}{ Goats } & & \multicolumn{3}{|c|}{$500 \mathrm{~m}$ buffer } & \multicolumn{3}{|c|}{$1000 \mathrm{~m}$ buffer } \\
\hline & & $\begin{array}{l}\text { Cases } \\
N=83\end{array}$ & $\begin{array}{l}\text { Controls } \\
N=858\end{array}$ & Adj OR $(95 \%$ CI) & $\begin{array}{l}\text { Cases } \\
N=83\end{array}$ & $\begin{array}{l}\text { Controls } \\
N=858\end{array}$ & Adj OR $(95 \% \mathrm{CI})$ \\
\hline \multirow[t]{2}{*}{ Home buffers only } & Goats in vicinity of home & 9 & 17 & $6.2(2.2-16.5)$ & 23 & 119 & $2.5(1.4-4.3)$ \\
\hline & No Goats in vicinity of home & 74 & 841 & Ref. & 60 & 739 & Ref. \\
\hline \multirow[t]{3}{*}{ Animals close to home + while in transport ${ }^{\mathrm{a}}$} & Goats in vicinity of home and GPS track & 9 & 17 & $6.2(2.2-16.9)$ & 22 & 118 & $2.5(1.3-4.7)$ \\
\hline & Only goats in vicinity GPS track & 21 & 219 & $1.0(0.6-1.7)$ & 30 & 330 & $1.1(0.6-1.9)$ \\
\hline & No goats in vicinity of home and GPS track & 53 & 622 & Ref. & 30 & 409 & Ref. \\
\hline \multirow[t]{4}{*}{ Outdoors close to home } & Goats in vicinity of home, long period outdoors & 7 & 7 & $12.7(3.6-45.4)$ & 14 & 56 & $3.0(1.4-6.2)$ \\
\hline & Goats in vicinity of home, short period outdoors & 2 & 10 & $2.0(0.3-9.2)$ & 9 & 63 & $1.9(0.8-4.1)$ \\
\hline & No goats in vicinity of home, long period outdoors & 37 & 407 & $1.0(0.6-1.6)$ & 30 & 358 & $1.0(0.6-1.7)$ \\
\hline & $\begin{array}{l}\text { No goats in vicinity of home, short period } \\
\text { outdoors }\end{array}$ & 37 & 434 & Ref. & 30 & 381 & Ref. \\
\hline
\end{tabular}

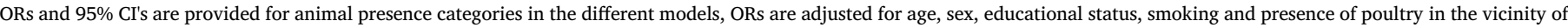

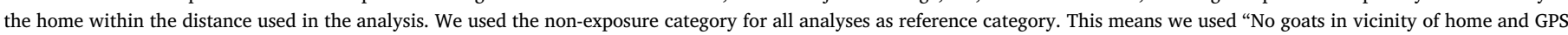

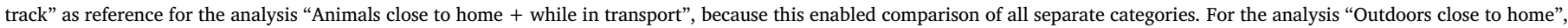
we used "No goats in vicinity of home, short period outdoors" as reference, again to enable comparison of all separate categories in the analyses.

${ }^{a}$ One case and 1 control were removed from the analysis using $1000 \mathrm{~m}$ buffers because of power limitations, these fell within the category "Goats in vicinity of home, no goats in vicinity of GPS track".

Der Hoek et al., 2012). It has been suggested that previous infection with Coxiella burnetii (the causative agent of Q-fever) may add an increased sensitivity to other infectious agents (Hussain-Yusuf et al., 2012; Marmion et al., 2009; Raoult et al., 2005; Waag, 2007; Keijmel et al., 2016; Hatchette et al., 2003; Morroy et al., 2011). It is relevant to note that at the time of our study, Q-fever incidence had dropped again to pre-epidemic levels (Freidl et al., 2017). Moreover, all study participants underwent serological testing for antibodies against $C$. burnetii, as part of the health assessment of the VGO study (Borlée et al., 2017). In line with previous research (Freidl et al., 2017), we re-evaluated Qfever serology and did not observe different levels of $C$. burnetii antibodies between people who had experienced pneumonia in the past three years and those who had not. This means that it is unlikely that a present or past Q-fever epidemic is underlying the increased pneumonia risk observed in our study. Few indications exist for other zoonoses that originate from goats. Rodolakis (2014) reviewed zoonoses from goats and identified two other agents that can potentially cause pneumonia in humans; Chlamydia abortus and Pasteurella multocida (Rodolakis, 2014). C. abortus is mainly a risk for pregnant women and has previously only been reported once in the Netherlands (Meijer et al., 2004). P. multocida can cause pneumonia, but is more often isolated from skin lesions (Mohamed and Abdelsalam, 2008) and has, to the best of our knowledge, so far never been isolated in the Netherlands. Overall, we were limited in our ability to explore the potential for these or other agents (e.g. viruses (Kallio-Kokko et al., 2005; Li et al., 2014), fungi (Libshitz, 1981) originating from the straw that is used inside stables (Hogerwerf et al., 2012), or thermophile fungi or bacteria originating from manure applied to the surrounding land (van den Brom et al., 2013)) as the underlying cause of pneumonia, given the lack of data regarding presence or absence of these agents.

We observed that active mobility close to goat or poultry farms did not strongly affect risk estimates and risk estimates were mainly driven by living close to goat farms. This might be due to the fact that total time in active transport was rather limited ( $20 \mathrm{~min} /$ week walking, $1 \mathrm{~h} /$ week biking) as was the time while in close distance to a farm while in active transport (Supp. Table 8), compared to time spent gardening (median $3.5 \mathrm{~h}$ /week).

Risks were more pronounced for people living close to goat farms

Table 3

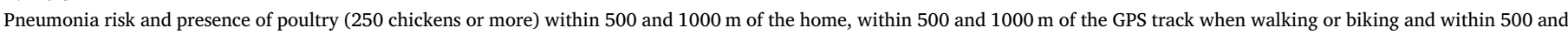
$1000 \mathrm{~m}$ of the home while being outdoors (gardening).

\begin{tabular}{|c|c|c|c|c|c|c|c|}
\hline \multirow[t]{2}{*}{ Poultry } & & \multicolumn{3}{|c|}{$500 \mathrm{~m}$ buffer } & \multicolumn{3}{|c|}{$1000 \mathrm{~m}$ buffer } \\
\hline & & $\begin{array}{l}\text { Cases } \\
N=83\end{array}$ & $\begin{array}{l}\text { Controls } \\
N=858\end{array}$ & Adj OR (95\% CI) & $\begin{array}{l}\text { Cases } \\
N=83\end{array}$ & $\begin{array}{l}\text { Controls } \\
N=858\end{array}$ & Adj OR $(95 \% \mathrm{CI})$ \\
\hline \multirow[t]{2}{*}{ Home buffers only } & Poultry in vicinity of home & 19 & 132 & $1.1(0.6-2.1)$ & 55 & 512 & $1.1(0.7-1.8)$ \\
\hline & No poultry in vicinity of home & 64 & 726 & Ref. & 28 & 346 & Ref. \\
\hline \multirow[t]{3}{*}{ Animals close to home + while in transport ${ }^{\mathrm{a}}$} & Poultry in vicinity of home and GPS track & 18 & 131 & $1.4(0.6-3.5)$ & 55 & 512 & $1.0(0.3-6.5)$ \\
\hline & Only poultry in vicinity GPS track & 54 & 559 & $1.5(0.8-3.2)$ & 26 & 317 & $0.9(0.3-6.1)$ \\
\hline & No poultry in vicinity of home and GPS track & 10 & 167 & Ref. & 2 & 29 & Ref. \\
\hline \multirow{4}{*}{ Outdoors close to home } & Poultry in vicinity of home, long period outdoors & 10 & 63 & $1.2(0.5-2.8)$ & 31 & 245 & $1.1(0.6-2.2)$ \\
\hline & Poultry in vicinity of home, short period outdoors & 9 & 69 & $1.1(0.4-2.6)$ & 24 & 267 & $0.8(0.4-1.7)$ \\
\hline & $\begin{array}{l}\text { No poultry in vicinity of home, long period } \\
\text { outdoors }\end{array}$ & 34 & 351 & $1.1(0.6-1.8)$ & 13 & 169 & $0.8(0.4-1.7)$ \\
\hline & $\begin{array}{l}\text { No poultry in vicinity of home, short period } \\
\text { outdoors }\end{array}$ & 30 & 375 & Ref. & 15 & 177 & Ref. \\
\hline
\end{tabular}

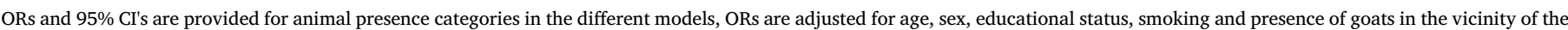

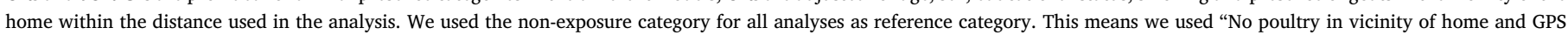

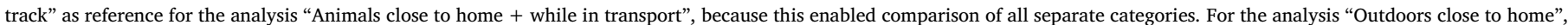
we used "No poultry in vicinity of home, short period outdoors" as reference, again to enable comparison of all separate categories in the analyses.

${ }^{a}$ One case and 1 control were removed from the analysis using $500 \mathrm{~m}$ buffers because of power limitations, these fell within the category "Poultry in vicinity of home, no poultry in vicinity of GPS track". 


\section{A. Outdoors and Pneumonia, goats within $500 \mathrm{~m}$}

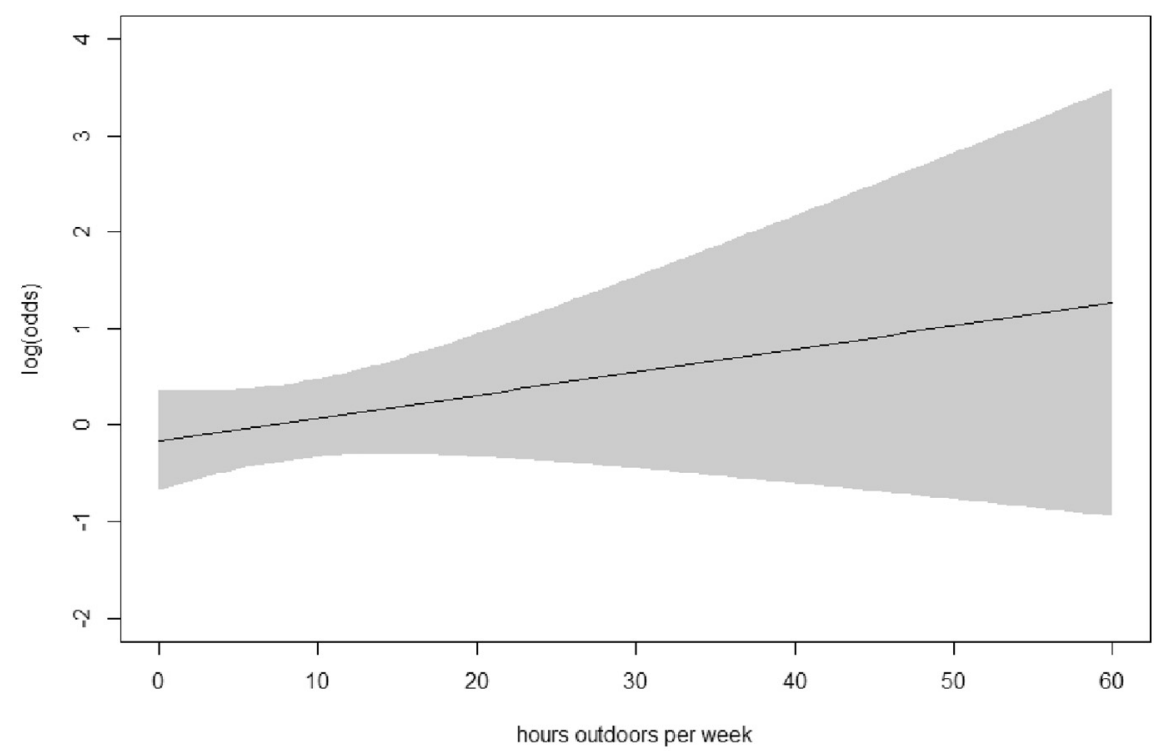

B. Outdoors and Pneumonia, goats within $1000 \mathrm{~m}$

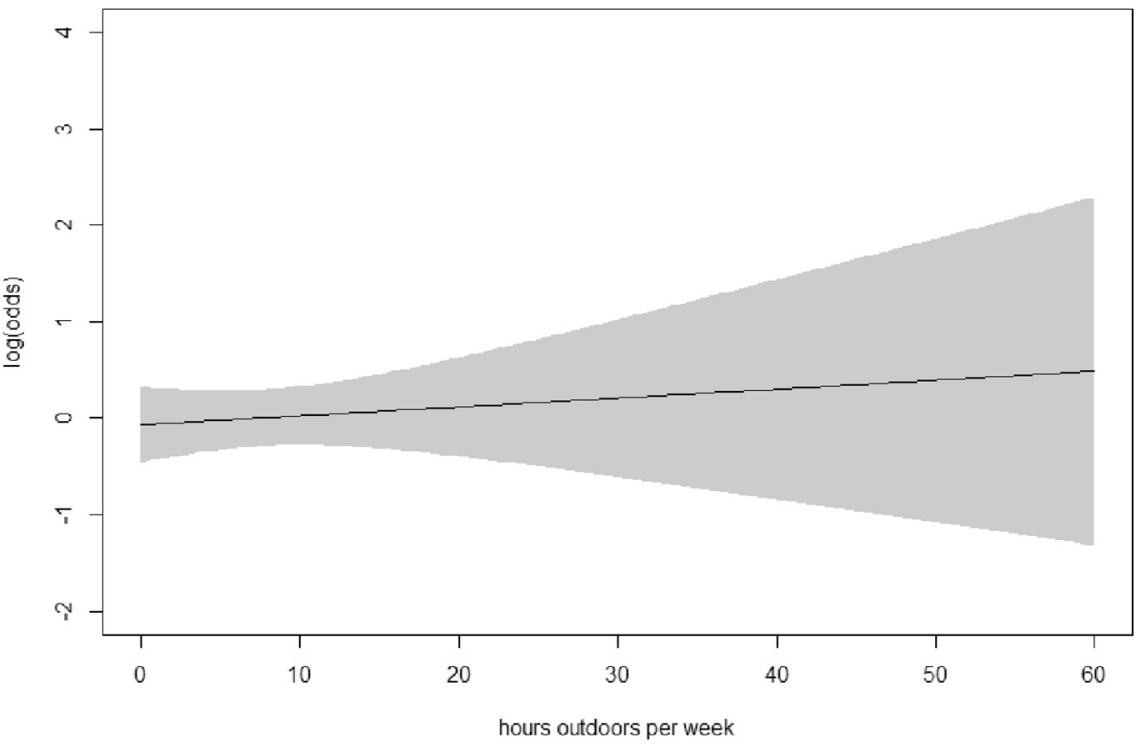

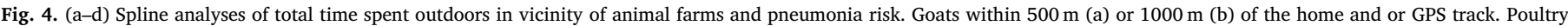
within $500 \mathrm{~m}$ (c) or $1000 \mathrm{~m}$ (d) of the home and or GPS track.

who spent more time outdoors close to home (primarily on gardening), however the number of cases and controls in this group was very limited. Still, time spent outdoors in locations that were not close to goat farms did not translate into increased risks, which suggests that gardening as such is not a risk factor. The spline analyses we performed also showed that more time spent outdoors in the vicinity of goat farms seemed to be associated with an increasing pneumonia risk (Fig. 4a and b). The association between time spent outdoors close to home in the vicinity of goat farms and pneumonia risk also remained present when we performed this analysis in the full VGO cohort $(N=2426)$. We observed similar patterns (Supp. Table 7), strengthening the notion that pneumonia risks were associated with time spent outdoors in locations close to goat farms.

For poultry in the vicinity of homes we observed a small, statistically non-significant increase of risk for pneumonia. Observed risks are in line with an earlier analysis among $>100,000$ individuals using EMR data in the same region (Smit et al., 2017). The authors speculated that dust and endotoxin emissions from poultry might explain this excess risk (Smit et al., 2017), since fine dust is a known causative agent for pneumonia (Cheng et al., 2008) and other lung diseases (Brauer et al., 2002). According to a recent national report (Netherlands Government, n.d.), goat farms emit much lower levels of fine dust compared to poultry farms (Supp. Table 9). This means that fine dust exposure from animal keeping is less likely to explain excess risk for pneumonia from goat farms than it is for poultry farms. In summary, we have no explanation for the underlying causative agent responsible for the increased pneumonia risk related to goat farms in our study. 


\section{Outdoors and Pneumonia, poultry within $500 \mathrm{~m}$}

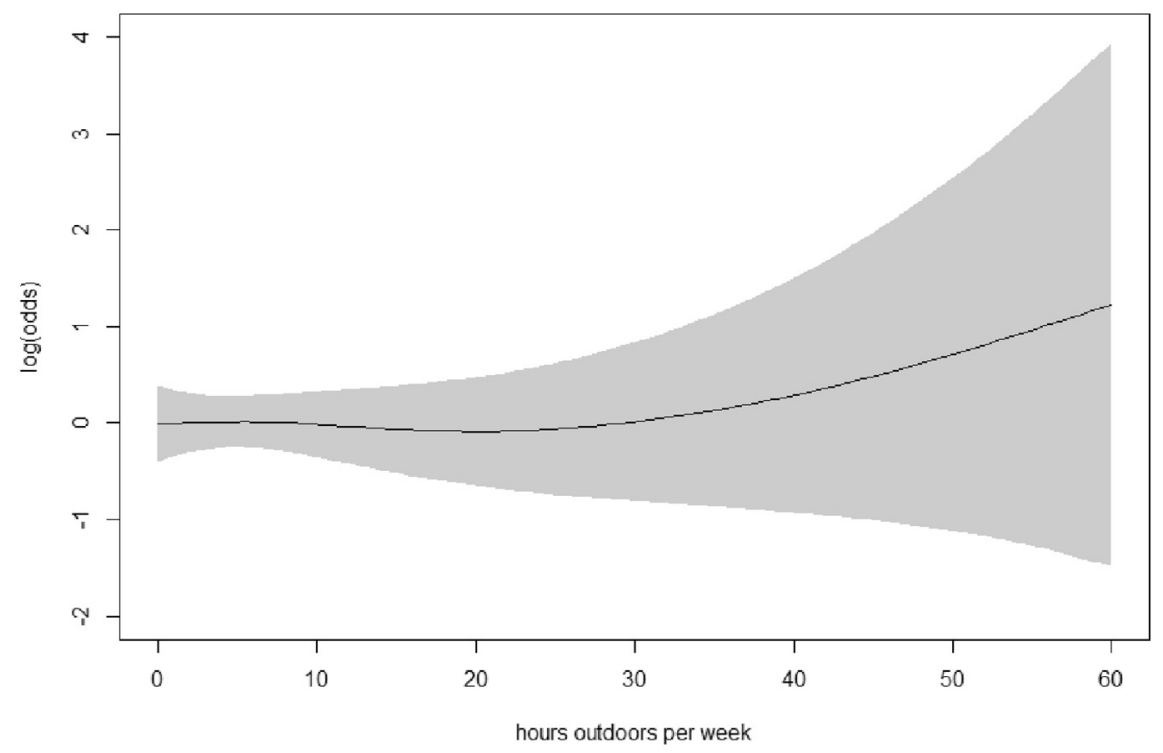

D. Outdoors and Pneumonia, poultry within $1000 \mathrm{~m}$

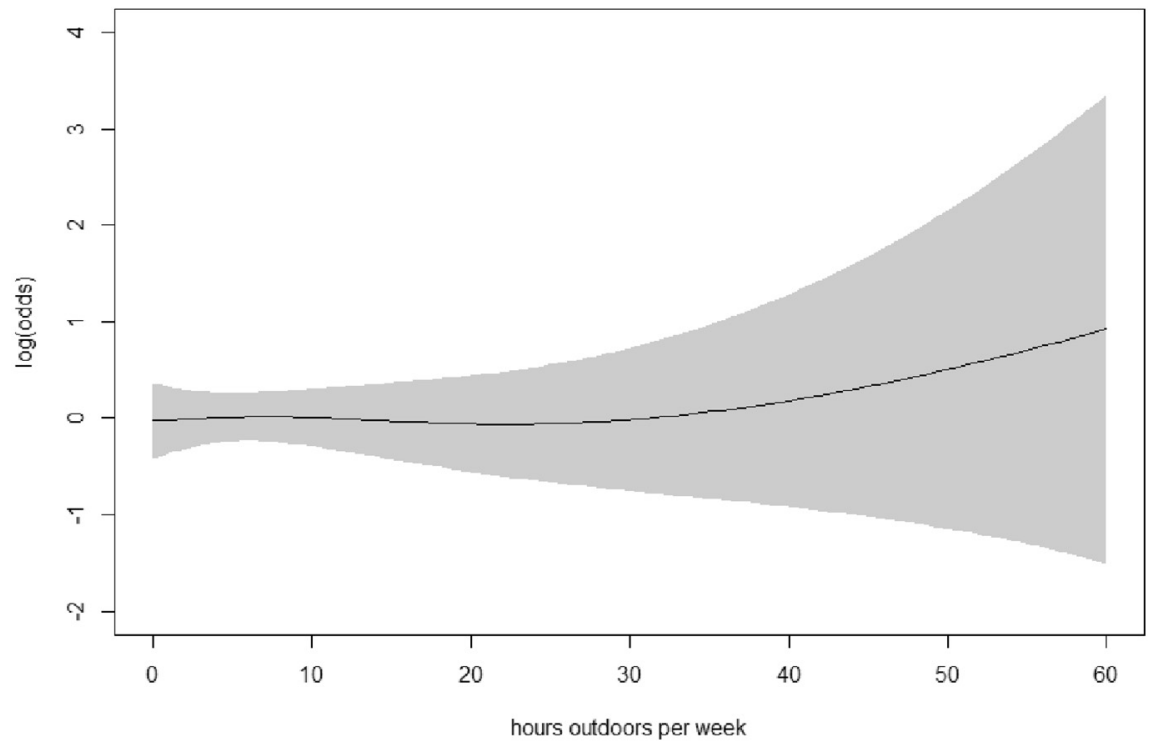

Fig. 4. (continued)

\subsection{Strengths and limitations}

A strength of our study is that we had measured mobility data of a relatively large cohort $(N=941)$ (Klous et al., 2017). In addition, the cohort included self-reported information about time spent outdoors. Furthermore, we had information about participants' health and lifestyle, age, gender, education level, smoking status and whether they lived in the vicinity of goats and/or poultry. Although nearly $9 \%$ of our participants had had a pneumonia in recent years and we have an extensive dataset for our study population, the overall population size $(N=941)$ might be too small to observe minor increases in risk for pneumonia.

Mobility patterns may change over time and this may not be well captured in our data. Still, we tracked 941 study participants during the time frame of over one year. Therefore, misclassification on the individual level may be present in our study, but the data should also reflect a representative picture of mobility patterns in our population. Active mobility contributed only a limited amount to the total time spent outdoors because the majority of time spent outdoors was spent in the vicinity of the home.

Another limitation of our study relates to using GP electronic patient records where we do not know which diagnostic procedure was underlying the pneumonia diagnosis. The occurrence of pneumonia was relatively high (nearly 9\%) in our study population. We considered people as cases if they had had a pneumonia in the last 3 years. This increased pneumonia incidence in our study area, compared to the whole of the Netherlands, is an ongoing trend since 2007. Van Dijk et al. studied pneumonia prevalence in our study area and found an increased pneumonia risk over the years (average prevalence 2007-2013 16.3/1000 patients) when compared to a control rural area with a lower livestock density (average prevalence 2007-2013 11.9/ 1000 patients) (van Dijk et al., 2017). Given the recent Q-fever 
epidemic, it is conceivable that doctors were more prone to diagnose a pneumonia in our rural study area. Therefore, we cannot exclude that information bias might have contributed to the observed increased risks of pneumonia, especially when GPs were aware about the location of their patients' homes and the location of farms in the residential area. However, a nation-wide analysis of hospital admissions for pneumonia over the years 2012-2014 suggests clustering of pneumonia admissions in livestock-dense regions (Benincà et al., 2017). Furthermore, information bias does not explain the strong increase in pneumonia risk for people spending more time outdoors close to home, since this is not evaluated in pneumonia diagnosis.

We also classified participants as "cases" if they reported a doctordiagnosed pneumonia that was not corroborated by the GP records. If participants misinterpreted their GPs diagnosis of e.g. an acute bronchitis or upper respiratory tract infection as pneumonia, and if these participants lived closer to goat farms, then this could have further contributed to differential misclassification. It might also be that for the questionnaire-based pneumonia cases, participants did not remember correctly the time of the diagnosis. However, in the analysis on the full cohort, excluding pneumonia cases if they were not confirmed by GP records had no material effect on risk estimates (Freidl et al., 2017). Within our subgroup of the VGO population, 33\% $(N=28)$ of the cases were assigned based on their questionnaire answers only, $66 \%(N=55)$ of cases had either an EMR R81 notification or were assigned as cases based on questionnaire data and EMR data. When we performed our analyses assigning cases only based on an EMR R81 notification, the results of our analyses also remained materially unchanged (Supplementary data, Supp. Tables 5 and 6).

The invitation method we applied might have had an effect on our study, we observed a significant difference in group sizes of exposed participants between invited and non-invited VGO cohort members. An explanation might be that the non-invited group also included people invited to the COPD follow-up, previous work in the VGO study showed that participants with COPD lived less often in the vicinity of farms (Borlée et al., 2015).

With regards to the spatial analyses, we found no significant differences between invited participants with and without usable GPS tracks, concerning outcome and exposure. In order to increase our power for the statistical analyses, we included people with goats/ poultry within $500 \mathrm{~m}$ of the house also to the analyses with animals within $1000 \mathrm{~m}$ of the house. Which may lead to effect modification to some extent. However, when we performed the analyses with mutual exclusion we still observed a significantly increased OR for goats within 0-500 m (OR 6.7, 95\% CI 2.4-18.1) and a non-statistically significant increased OR for having goats within $500-1000 \mathrm{~m}$ of the home (OR 1.8, 95\% CI 0.9-3.4). For poultry within $500 \mathrm{~m}$ or $1000 \mathrm{~m}$, ORs where still above unity, but not statistically significant.

\subsection{Future research}

It is unclear what is underlying the observed increased pneumonia risks associated with proximity to goat farms and spending time outdoors close to goat farms. Additional research is required to identify the underlying cause of these increased risks. First, a veterinary survey would be informative to evaluate whether and which infectious agents are circulating among goats by applying molecular diagnostics such as whole genome sequencing and proteomics on samples obtained from animals (Cirulli and Goldstein, 2010; Köser et al., 2012; Ray et al., 2011). Second, if an infectious agent was identified among livestock, air samples could be taken in goat stables and their surroundings to check whether the agent is emitted to the environment. These environmental samples could then be analysed using more specific molecular techniques such as PCR (Hogerwerf et al., 2012). In a third step, samples obtained from human pneumonia cases and controls should be analysed using similar techniques (Zhang et al., 2010). If the infectious agent is found in each step, the relationship between the animal-origin pathogen, environmental transmission and human infections can be confirmed and the pathway clarified, providing opportunities for prevention.

\section{Conclusions}

Pneumonia risk in our study was increased if people lived within 500 or $1000 \mathrm{~m}$ of a goat farm. Mobility outdoors in the vicinity of goat farms did not markedly change risk estimates, but this could be expected given that the time spent outside was relatively limited. Time spent outdoors close to home in the presence of goat farms translated into a significantly increased pneumonia risk. As it is unknown which specific agent or mechanism is underlying the observed increased risk, this needs further study.

\section{Acknowledgements}

We like to thank all the participants, Myrna de Rooij for statistical input, Daisy de Vries for textual input and George Downward for a final language edit of the manuscript.

\section{Appendix A. Supplementary data}

Supplementary data to this article can be found online at https:// doi.org/10.1016/j.envint.2018.03.020.

\section{References}

www.cbs.nl Landsurface Netherlands [Internet]. Available from. http://statline.cbs.nl/ Statweb/publication/?DM $=$ SLNL\&PA $=70262$ ned \&D $1=0-2 \& D 2=0-4 \& D 3=3-7 \&$ $\mathrm{VW}=\mathrm{T}$.

www.cbs.nl Population Netherlands [Internet]. Available from. http://statline.cbs.nl/ Statweb/publication/?DM $=$ SLNL\&PA $=37296$ ned $\& D 1=0-2,19-28,52-58,68 \& D 2=$ $0,10,20,30,40,50,(1-1)-1 \& V W=T$.

www.cbs.nl Livestock Netherlands [Internet]. Available from. http://statline.cbs.nl/ Statweb/publication/?DM $=$ SLNL\&PA $=81302$ NED $\& D 1=387-536 \& D 2=0,5,10,13$ $16 \& \mathrm{HDR}=\mathrm{G} 1 \& \mathrm{STB}=\mathrm{T} \& \mathrm{VW}=\mathrm{T} /$.

www.wur.nl Poultry sector Netherlands [Internet]. Available from. http://www.wur.nl/ $\mathrm{nl} /$ artikel/Kort-overzicht-economisch-belang-Nederlandse-pluimveesector.htm.

Benincà, E., Van Boven, M., Hagenaars, T., Van Der Hoek, W., 2017. Space-time analysis of pneumonia hospitalisations in the Netherlands. PLoS One 12 (7), 1-14.

Bieleman, J., 2008. Boeren in Nederland, geschiedenis van de landbouw 1500-2000. Amsterdam.

Borlée, F., Yzermans, C.J., Van Dijk, C.E., Heederik, D., Smit, L.A.M., 2015. Increased respiratory symptoms in COPD patients living in the vicinity of livestock farms. Eur. Respir. J. [Internet] 46 (6), 1605-1614. Available from. https://doi.org/10.1183/ $13993003.00265-2015$.

Borlée, F., Yzermans, C.J., Krop, E., Aalders, B., Rooijackers, J., Zock, J.P., et al., 2017. Spirometry, questionnaire and electronic medical record based COPD in a population survey: comparing prevalence, level of agreement and associations with potential risk factors. PLoS One 12 (3), 1-16.

Brauer, M., Hoek, G., Van Vliet, P., Meliefste, K., Fischer, P.H., Wijga, A., et al., 2002. Air pollution from traffic and the development of respiratory infections and asthmatic and allergic symptoms in children. Am. J. Respir. Crit. Care Med. 166 (8), 1092-1098.

van den Brom, R., Schimmer, B., Schneeberger, P.M., Swart, W.A., van der Hoek, W., Vellema, P., 2013. Seroepidemiological survey for Coxiella burnetii antibodies and associated risk factors in Dutch livestock veterinarians. PLoS One 8 (1), 1-5.

Cheng, M.F., Ho, S.C., Chiu, H.F., Wu, T.N., Chen, P.S., Yang, C.Y., 2008. Consequences of exposure to Asian dust storm events on daily pneumonia hospital admissions in Taipei, Taiwan. J. Toxicol. Environ. Health - Part A Curr. Issues 71 (19), 1295-1299.

Cirulli, E.T., Goldstein, D.B., 2010. Uncovering the roles of rare variants in common disease through whole-genome sequencing. Nat. Rev. Genet. [Internet] Nature Publishing Group 11 (6), 415-425. Available from. http://www.nature.com/ doifinder/10.1038/nrg2779.

De Rooij, M.M.T., Heederik, D.J.J., Borlée, F., Hoek, G., Wouters, I.M., 2017. Spatial and temporal variation in endotoxin and PM10 concentrations in ambient air in a livestock dense area. Environ. Res. [Internet] Elsevier 153 (September 2016), 161-170. Available from. https://doi.org/10.1016/j.envres.2016.12.004.

van Dijk, C.E., Zock, J.P., Baliatsas, C., Smit, L.A.M., Borlée, F., Spreeuwenberg, P., et al., 2017. Health conditions in rural areas with high livestock density: analysis of seven consecutive years. Environ. Pollut. 222, 374-382.

Freidl, G.S., Spruijt, I.T., Borlée, F., Smit, L.A.M., Van Gageldonk-Lafeber, A.B., Heederik, D.J.J., et al., 2017. Livestock-associated risk factors for pneumonia in an area of intensive animal farming in the Netherlands. PLoS One 12 (3), 1-16.

Graveland, H., Wagenaar, J.A., Bergs, K., Heesterbeek, H., Heederik, D., 2011. Persistence of livestock associated MRSA CC398 in humans is dependent on intensity of animal 
contact. PLoS One 6 (2), 1-7.

Hatchette, T.F., Hayes, M., Merry, H., Schlech, W.F., Marrie, T.J., 2003. The effect of $C$. burnetii infection on the quality of life of patients following an outbreak of Q fever. Epidemiol. Infect. [Internet] 130 (3), 491-495. Available from. http://www. pubmedcentral.nih.gov/articlerender.fcgi $?$ artid $=2869986 \&$ tool $=$ pmcentrez $\&$ rendertype $=$ abstract

Hogerwerf, L., Borlée, F., Still, K., Heederik, D., van Rotterdam, B., de Bruin, A., et al., 2012. Detection of Coxiella burnetii DNA in inhalable airborne dust samples from goat farms after mandatory culling. Appl. Environ. Microbiol. 78 (15), 5410-5412.

Huss, A., Beekhuizen, J., Kromhout, H., Vermeulen, R., 2014. Using GPS-derived speed patterns for recognition of transport modes in adults. Int. J. Health Geogr. [Internet] 13 (1), 40 (Available from: http://www.pubmedcentral.nih.gov/articlerender.fcgi? artid $=4320483 \&$ tool $=$ pmcentrez\&rendertype $=$ abstract $\backslash$ nhttp: $/ / \mathrm{ij}$ healthgeographics.biomedcentral.com/articles/10.1186/1476-072X-13-40).

Hussain-Yusuf, H., Islam, A., Healy, B., Lockhart, M., Nguyen, C., Sukocheva, O., et al., 2012. An analysis of Q fever patients 6 years after an outbreak in Newport, Wales, UK. QJM 105 (11), 1067-1073.

Jones, K.E., Patel, N.G., Levy, M.A., Storeygard, A., Balk, D., Gittleman, J.L., et al., 2008. Global trends in emerging infectious diseases. Nature 451 (7181), 990-993.

Kallio-Kokko, H., Uzcategui, N., Vapalahti, O., Vaheri, A., 2005. Viral zoonoses in Europe. FEMS Microbiol. Rev. 29 (5), 1051-1077.

Keijmel, S.P., Raijmakers, R.P.H., Bleeker-Rovers, C.P., van der Meer, J.W.M., Netea, M.G., Schoffelen, T., et al., 2016. Altered interferon- $\gamma$ response in patients with Qfever fatigue syndrome. J. Infect. [Internet] Elsevier Ltd. 72 (4), 478-485. Available from. https://doi.org/10.1016/j.jinf.2016.01.004.

Klous, G., Huss, A., Heederik, D.J.J., Coutinho, R.A., 2016. Human-livestock contacts and their relationship to transmission of zoonotic pathogens, a systematic review of literature. One Health 2, 65-76. Available from. https://doi.org/10.1016/j.onehlt. 2016.03.001.

Klous, G., Smit, L.A.M., Borlée, F., Coutinho, R.A., Kretzschmar, M.E.E., Heederik, D.J.J., et al., 2017. Mobility assessment of a rural population in the Netherlands using GPS measurements. Int. J. Health Geogr. [Internet] BioMed. Central 16 (1), 30. Available from. http://ij-healthgeographics.biomedcentral.com/articles/10.1186/s12942017-0103-y.

Köser, C.U., Ellington, M.J., Cartwright, E.J.P., Gillespie, S.H., Brown, N.M., Farrington, M., et al., 2012. Routine use of microbial whole genome sequencing in diagnostic and public health microbiology. PLoS Pathog. 8 (8).

Lamberts, H., Wood, M., 1987. International Classification of Primary Care. Oxford University Press.

Li, W., Mao, L., Cheng, S., Wang, Q., Huang, J., Deng, J., et al., 2014. A novel parainfluenza virus type 3 (PIV3) identified from goat herds with respiratory diseases in eastern China. Vet. Microbiol. [Internet] Elsevier B.V. 174 (1-2), 100-106. Available from. https://doi.org/10.1016/j.vetmic.2014.08.027.

Libshitz, I., 1981. Aspergillosis and Mucormycosis: Two Types of Opportunistic Fungal. pp. 301-306.

Limburg BVB Limburg. Available from. http://www.limburg.nl.

Marmion, B.P., Sukocheva, O., Storm, P.A., Lockhart, M., Turra, M., Kok, T., et al., 2009. Q fever: persistence of antigenic non-viable cell residues of Coxiella burnetii in the host - implications for post $\mathrm{Q}$ fever infection fatigue syndrome and other chronic sequelae. QJM 102 (10), 673-684.

Meijer, A., Brandenburg, A., De Vries, J., Beentjes, J., Roholl, P., Dercksen, D., 2004. Chlamydophila abortus infection in a pregnant woman associated with indirect contact with infected goats. Eur. J. Clin. Microbiol. Infect. Dis. 23 (6), 487-490.

Mohamed, R.A., Abdelsalam, E.B.A., 2008. Review on pneumonic Pasteurellosis (respiratory mannheimiosis) with emphasis on pathogenesis, virulence mechanisms and predisposing factors. Bulg. J. Vet. Med. 11 (3), 139-160.

Morroy, G., Peters, J.B., Van Nieuwenhof, M., Hj Bor, H., La Hautvast, J., Van Der Hoek, W., et al., 2011. The health status of Q-fever patients after long-term follow-up. BMC Infect. Dis. [Internet] BioMed. Central Ltd. 11 (1), 97. Available from. http://www. biomedcentral.com/1471-2334/11/97.

Netherlands Government Livestock finedust [Internet]. Available from. https://www. rijksoverheid.nl/onderwerpen/luchtkwaliteit/documenten/publicaties/2017/03/ 15/emissiefactoren-fijn-stof-voor-veehouderij-2017.

Noord-Brabant BVB Brabant [Internet]. Available from. http://bvb.brabant.nl.

Raoult, D., Marrie, T.J., Mege, J.L., 2005. Natural history and pathophysiology of Q fever. Lancet Infect. Dis. 5 (4), 219-226.

Ray, S., Reddy, P.J., Jain, R., Gollapalli, K., Moiyadi, A., Srivastava, S., 2011. Proteomic technologies for the identification of disease biomarkers in serum: advances and challenges ahead. Proteomics 11 (11), 2139-2161.

Rodolakis, A., 2014. Zoonoses in goats: how to control them. Small Rumin Res. [Internet] Elsevier B.V. 121 (1), 12-20. Available from. https://doi.org/10.1016/j. smallrumres.2014.01.007.

Smit, L.A.M., van der Sman-de Beer, F., Opstal-van Winden, A.W.J., Hooiveld, M., Beekhuizen, J., Wouters, I.M., et al., 2012. Q fever and pneumonia in an area with a high livestock density: a large population-based study. PLoS One 7 (6).

Smit, L.A.M., Boender, G.J., de Steenhuijsen Piters, W.A.A., Hagenaars, T.J., Huijskens, E.G.W., Rossen, J.W.A., et al., 2017. Increased risk of pneumonia in residents living near poultry farms: does the upper respiratory tract microbiota play a role? Pneumonia [Internet] 9 (1), 3. Available from. http://pneumonia.biomedcentral com/articles/10.1186/s41479-017-0027-0.

Van Der Hoek, W., Morroy, G., Renders, N.H.M., Wever, P.C., Hermans, M.H.A., Leenders, A.C.A.P., et al., 2012. Coxiella burnetii: recent advances and new perspectives in research of the Q fever bacterium [Internet]. 329-364 p. Available from. http://link. springer.com/10.1007/978-94-007-4315-1.

Waag, D.M., 2007. Coxiella burnetii: host and bacterial responses to infection. Vaccine 25 (42), 7288-7295.

Wielders, C.C.H., van Hoek, A.H.A.M., Hengeveld, P.D., Veenman, C., Dierikx, C.M., Zomer, T.P., et al., 2017. Extended-spectrum $\beta$-lactamase- and pAmpC-producing Enterobacteriaceae among the general population in a livestock-dense area. Clin. Microbiol. Infect. [Internet] Elsevier Ltd. 23 (2), 120.e1-120.e8. Available from. https://doi.org/10.1016/j.cmi.2016.10.013.

Zhang, Z., Kermekchiev, M.B., Barnes, W.M., 2010. Direct DNA amplification from crude clinical samples using a PCR enhancer cocktail and novel mutants of Taq. J. Mol. Diagn. [Internet] Am. Soc. Invest. Pathol. Assoc. Mol. Pathol. 12 (2), 152-161. Available from. http://linkinghub.elsevier.com/retrieve/pii/S1525157810600438. 